\title{
Human cytomegalovirus infection as a lifelong health problem
}

\author{
Magdalena Figlerowicz ${ }^{1,2}{ }^{*}$, Agnieszka Modlińska-CWalińska ${ }^{1}$, AnNa Mania ${ }^{1}$, \\ Katarzyna Mazur-Melewska ${ }^{1}$, Pawee Kemnitz ${ }^{1}$, \\ KATARZYNa JoŃCZYK-Potoczna ${ }^{3}$, WOJCIECH SŁUŻEWSKI ${ }^{1}$ \\ ${ }^{1}$ Department of Infectious Diseases and Child Neurology, Poznan University of Medical Sciences, Poznań, Poland \\ ${ }^{2}$ The President Stanislaw Wojciechowski Higher Vocational State School in Kalisz, Kalisz, Poland \\ ${ }^{3}$ Department of Paediatric Radiology, Poznan University of Medical Sciences, Poznań, Poland \\ *Corresponding author: mfiglerowicz@gmail.com
}

\begin{abstract}
Infections with human cytomegalovirus (HCMV) are widely spread worldwide. A clinical picture of the infection varies and depends on the age of the patient and the condition of the immune system. Rapid dissemination of HCMV is related to the presence of the virus in the peripheral blood cells. The most severe course of the disease is observed in patients with congenital cytomegaly, organ transplant recipients and patients with either acquired or inborn immune deficiencies. Chronic HCMV infection may lead to atherosclerosis and as a consequence, to cardiovascular diseases such as: myocardial ischemia or infarction and hypertension. In addition, the relation between HCMV infection and neoplastic transformation was noticed. Since diagnostic and therapeutic methods are still imperfect, a development of an effective vaccine seems to be of key importance for a significant reduction of the consequences of HCMV infection.
\end{abstract}

Key words: HCMV, children, health problems

\section{Introduction}

Infections with human cytomegalovirus (HCMV) belong to the most frequent infections worldwide. HCMV is the largest member of Herpesviridae family with the virion diameter of $200 \mathrm{~nm}$ and double-stranded DNA genome (Murhy et al., 1957; Gerhz, 1991; Pass, 2001). This virus is responsible for many fetal defects, neonatal inborn malformations and various syndromes in children and adults. The clinical course of HCMV infection is mostly asymptomatic. Subclinical courses of the infection, a mononucleosis-like syndrome and disseminated HCMV infections have also been reported (Ho, 1990; Peterslund, 1991; Milewska-Bobula et al., 1992; Ho, 2008).

Various body fluids containing the virus (e.g., saliva, breast milk, vaginal secretions, semen, urine, stool, blood), tissues and organ transplants may be the source of infection. HCMV infections affect inhabitants of welldeveloped as well as developing countries. The proportion of people with specific antibodies that indicate previous HCMV infection is estimated as 50\% in Europe, the USA and Australia and 100\% in Africa and South Asia (Cannon et al.2005; Campbell et al. 2008). The incidence of congenital HCMV infection was found in 0.3 to $2.4 \%$ of neonates in the USA. And yet, the risk significantly increases in countries with lower economic status (Alford et al., 1990).

Many organ transplant recipients suffer from cytomegaly, which may be a consequence of HCMV infected organ transplantation or reactivation of latent infection in the host due to conducted immunosuppressive treatment. HCMV can also be transmitted during transfusions of blood and blood products (Ho, 2008).

Presence of HCMV in peripheral blood cells helps in the spread of the virus through the whole organism. Vesicular endothelial cells play a key role in the process (Sinzger, 2008) as they may facilitate the infection through:

- HCMV transmission to granulocytes, which transport viral particles to remote areas without being infected themselves (Gerna et al., 2000; Grefte et al., 1994; Grundy et al., 1998), 
- HCMV transmission to monocytes, which facilitate viral entry to the tissues when they differentiate into tissue macrophages (Sinzger et al., 1996),

- sequestration of infected endothelial cells containing latent forms of the virus from vascular wall and their transport with the blood flow (Grefte et al., 1993; Precivalle et al., 1993).

\section{Clinical picture}

The majority of acquired infections are asymptomatic. In older children, adolescents and in adults, mononucleosis-like syndrome may be observed. A clinical picture includes fever, malaise, lympadenopathy, muscle pains, headaches, liver and spleen enlargement, increased aminotransferase activity and atypical lymphocytes in peripheral blood. In immunocompromised patients, organ transplants recipients and in patients with AIDS, HCMV may be accompanied by various complications such as: pneumonia, nephritis or gastroenteritis of a severe or even fatal course. A primary HCMV infection occurs in individuals with no previous contact with the virus. The recurrence of the disease may be a result of the reactivation of latent infection or the re-infection with the virus. In children, the most dangerous problems are related to congenital cytomegaly (Ho, 2008; Malarowska et al., 2009).

\section{Congenital cytomegaly}

HCMV was found to multiply in the placenta. Intrauterinal HCMV infection causes congenital cytomegalovirus inclusion syndrome in $5-12.7 \%$ of the children. The characteristic features of the syndrome include: prematurity, liver and spleen enlargement, jaundice, thrombocytopenia, coagulopathies, microcephaly, intracranial calcifications, chorioretinits and deafness. In approximately $5 \%$ of children, clinical symptoms are moderate and in around $90 \%$ of patients, HCMV infection has an asymptomatic course, leading, however, to the chronic infection. Moreover, in children suffering from the disease, a worse intellectual development is observed, and this is accompanied by speech impairment and poorer language skills (Zhang et al., 2007; Malm and Engman, 2007).

\section{Perinatal infections}

Perinatal HCMV infections are present in 10-60\% of children whose mothers underwent a primary infec- tion. The infection may occur during the delivery (6-12\%) or the breastfeeding (50\%) despite the acquisition of a passive immunity (specific antibodies) during the pregnancy. In $32 \%$ of HCMV-infected mothers (having specific IgG antibodies), viral particles are present in the breast milk, resulting in $69 \%$ of their children becoming infected. In the mature neonates, acquired cytomegaly has usually an asymptomatic or a mild course. However, sporadic cases of pneumonia or multiorgan infections are also described. In the majority of children infected in perinatal period, neither clinical symptoms of the infection nor remote consequences are observed. HCMV infection in the neonatal period may occur due to blood transfusions. In such cases, clinical course of the disease is severe or even fatal (Hamprecht et al., 2008).

In the majority of people, the virus is not eradicated after primary infection but stays in the latent phase in various cell types, such as peripheral blood cells (mostly mononuclear cells), bone marrow cells, reticulo-endothelial cells of the lymph nodes, endothelial cells or kidney cells (Figlerowicz et al., 2011). The viral genome is present in infected cells, but no infective particles are created (Sinclair, 2008). Periodic reactivation of the virus is a frequent phenomenon, but can be quickly restricted with healthy immune system of the host (Sinclair, 2008).

Opinions concerning potential consequences of a chronic HCMV infection were recently changed with the emergence of new ideas related to the pathogenesis of many diseases. One of the important impulses was the discovery of the relation between Helicobacter pylori infection and peptic ulcers.

\section{HCMV infection and atherosclerosis}

Observations from recent years show that HCMV infection may influence the development of cardiovascular diseases such as: myocardial ischemia, myocardial infarction, hypertension and atherosclerosis. The progression of hypertension is also related to the infections with other viruses (Epstein-Barr virus, the Human Herpes virus type 8 , enteroviruses, adenoviruses or human immunodeficiency virus type 1) or bacteria (Chlamydia pneumoniae, Mycoplasma pneumoniae) (Ismail et al., 1999, Cheng et al., 2009, Al-Ghamdi et al., 2011).

The mechanism(s) that connect viral infection with the initiation of atherosclerosis and hypertension are not clear yet. Atherosclerosis was considered to be a dege- 
nerative disease of the vessels characterized by the deposition of atheromatous plaques in the innermost layer of the vascular wall. Currently, a chronic inflammatory reaction is considered to play a key role in the pathogenesis of the process, beside lipid disorders and genetic predispositions (Ismail et al., 1999).

A key phase in the formation of an atheromatous plaque is the presentation of the antigen by the macrophages to the T-cells. This antigen may be a fragment of oxydated low density protein (oxLDL), thermal shock proteins (e.g. $\beta$-glycoprotein), or fragments of viral and bacterial antigens. The presence of $\mathrm{CD} 40$ receptor on the surface of the macrophages and CD40 ligand (CD40L) on the surface of T-cells is crucial to the mutual interaction of these cells. Their binding activates both the cellular (T helper 1-Th1) and the humoral (T helper 2-Th2) immune response. It was discovered that Th1 type of the immune response facilitates the progression of atherosclerosis through its mediators: interleukins (IL) - IL-1, -6,-12 and -18, tumor necrosis factor alpha (TNF- $\alpha$ ) and interferon gamma (IFN- $\gamma$ ) (Waller, 2008). On the other side, the deceleration of the inflammatory process is activated by the immune response $\mathrm{Th} 2$ and its mediators IL-4,-5,-10 and 13 (Daley et al., 2008).

In adults, atherosclerosis is usually detected at the stage of the deposition of lipids and foam cells in internal lamina of the arteries. It has recently been suggested that more subtle lesions within the arterial wall have a key role in atherogenesis, i.e. the chemotaxia of inflammatory cells and the activation of cytokine cascade ( $\mathrm{Sa}-$ etta et al., 2000; van de Berg et al., 2008). These lesions are believed to be formed during the second decade of human life. Moreover, the accumulation of low density lipoproteins (LDL) in the subendothelial space leads to the atheromatous plaque. A chronic inflammatory state leads to their transformation into oxLDL, which are much easier phagocytized by activated macrophages ( $\mathrm{Sa}-$ etta et al., 2000; van de Berg et al., 2008).

One of the markers of the inflammatory process is intercellular adhesive molecule-1 (ICAM-1). This molecule belongs to the immunoglobulin family that determines the adhesion and the migration of cells in the inflammatory process. The concentration of its soluble form - a soluble intercellular adhesive molecule-1 (sICAM-1) in serum correlates with other markers of the inflammatory state like: C-reactive protein, the erythrocyte sedimentation rate, the high level of homocystein and intima-media complex thickness (IMT). The latter is a widely used early marker of the vascular lesion. IMT is related to high probability of the development of a clinical form of atherosclerosis. The baseline value of the IMT is $\geq 0.9 \mathrm{~mm}$ (Ismail et al., 1999).

Until now, no correlation has been found between the elevation of those parameters and the level of antibodies to HCMV in children. It is widely known that, like other Herpesviridae, HCMV has a tendency to stay during the latent phase. A decrease in the immune condition may cause a reactivation of the infection. Usually, it is a local reactivation within the arterial wall. Numerous results of transplanted organ biopsy specimens in patients during the immunosuppressive treatment seem to prove this finding. It has also been confirmed that HCMV causes a chronic inflammatory state of the internal wall of the arteries, leading to an increased sensitivity of the vessel to the accumulation of foamy cells, which, in a longer perspective, results in a quick growth and instability of an atheromatous plaque which is being formed. The modification of the immune response due to viral antigens seems to be a probable mechanism responsible for the induction of atherogenesis. This modification is caused by the production of proinflammatory cytokines through Th1 and Th2 cells, the macrophages and the endothelial cells. HCMV infection is related to a significantly increased level of oxidized forms of lipoproteins, especially oxLDL. Experiments carried on the mouse model and cellular cultures proved the influence of HCMV infection on the increase in the blood pressure, especially with a coexisting cholesterol-rich diet. In such cases, atheromatous plaques were found even in the main arteries. Furthermore, in a chronic HCMV infection, the activation of renin-angiotensin system was found, which significantly influences the progression of hypertension (Cheng et al., 2009).

The presence of short telomeres in the circulating T-cells is an approved risk factor of the progression of many age-related diseases, including cardiovascular problems and atherosclerosis. The mechanism that leads to the formation of telomeres of different lengths is still unclear. Telomeres are gene-poor regions at the end of chromosomes. They contain long repeats of TTAGGG sequences that protect chromosomes from alteration (inappropriate DNA repair and recombination). Because the 3 ' ends of linear DNA cannot be duplicated by DNA polymerase, telomeres shorten after each cell division. 
When telomeres reach a critical length, they cannot play their role, the cells grow old or undergo apoptosis. Although it has been established that telomere length shortens with age, it is not known why significant differences in their length are found in persons of the same age. Genetic factors, oxidative stress and chronic infection seem to be the probable reasons of this phenomenon. In the studies of van de Berg, 2010, a significant shortening of telomeres was demonstrated during the primary HCMV infection. Moreover, it was proved that the shortening of telomeres in HCMV-positive patients progresses faster than in individuals who are not HCMV infected and correlates with the number of CD4 and CD8 differentiation. It was also shown that the length of telomeres in lymphocytes correlates with the length of telomeres in the blood leucocytes (van de Berg et al., 2010).

\section{HCMV infection and malignancies}

Recent evidence indicates the presence of the HCMV DNA and its antigens in certain malignant tumors, including colon cancer, malignant glioblastoma, EBV-negative Hodgkin lymphoma, prostatic carcinoma and breast cancer. According to the reports (Soderberg-Naucler, 2006), $90-100 \%$ of these malignancies are HCMV infected. What is more, non-cancer cells in close surrounding of these tumors appear to be HCMV negative.

When the immune system identifies tumor cells, it may create a local inflammation. In such a situation, virus carried into inflamed area with HCMV-infected monocytes or macrophages may become reactivated. If the virus is transferred to the cancer cells, it is unlikely that the immune system will eliminate them. On the other hand, the virus is capable of controlling cellular differentiation, proliferation, migration, angiogenesis, DNA repair mechanisms, production and action of cytokines, chemokines and growth factors through numerous proteins. In this way, the virus would likely affect the developing tumor through the modulation of cellular processes. In addition, HCMV produces several anti-apoptotic proteins which may interfere with chemotherapy, and contribute to the resistance of virus-infected tumor cells to the treatment (Soderberg-Naucler, 2006).

\section{Diagnostics}

Acute HCMV infection can be detected by isolating the virus from: urine, saliva, bronchial washing return fluid, breast milk, vaginal secretions and biopsy speci- mens. The detection of HCMV antigens as well as HCMV-DNA is possible from various specimens.

In recent years, new reports have been published where the diagnosis of HCMV infection was based on the extraction and detection of viral DNA from the dry blood drop obtained to Guthrie test in the first days of life.

The differentiation between primary infection and reactivation of latent infection is based on the confirmation of the seroconversion or the coexistence of IgM and IgG antibodies in serum. After HCMV infection, IgG antibodies are detected through the whole life. IgM antibodies sporadically appear in patients with relapsing infection $(0.2-1 \%)$. In immunocompromised patients, the virus is frequently found in body secretions, IgG titer rises and IgM antibodies are detected. Therefore, differentiation between a primary infection and a reactivation, which is extremely important in this group of patients, is very difficult (Ho, 2008).

\section{Treatment}

Currently, no antiviral treatment for individuals with normal immunity is recommended. In patients with congenital or acquired immune deficiency, intensive treatment with gancyclovir is used in combination with antiHCMV immunoglobulin. The toxicity of gancyclovir is significant and results in leucopenia, trombocytopenia, liver and kidney function deficits and the inhibition of spermatogenesis. Treatment of children with congenital cytomegaly is controversial and currently is recommended in severe cases of the diseases (Adler et al., 2007; Michaels, 2007). In adults, the drug is used with coexisting immune deficiency (patients receiving chemotherapy, organ transplant recipients, patients with AIDS).

\section{Prognosis}

Most patients with acquired cytomegaly recover. The course of the disease may be severe or even fatal in immunocompromised patients and in patients with special susceptibility to HCMV infection (patients with AIDS). In almost $90 \%$ of children with symptomatic congenital cytomegaly symptoms proving CNS deficits and hearing impairment are detected years after infection. Recently, it has been stressed that in children with asymptomatic congenital cytomegaly, remote development of hearing (5-10\%) and sight impairment (3-5\%) is also possible. Microcephaly and other CNS deficits are less frequent (Malm and Engman, 2007). 


\section{Prevention}

Pregnant women should be tested for anti-HCMV antibodies. If the result is positive, the risk of congenital cytomegaly in a child is relatively small. A negative result indicating that the female had no previous HCMV infection, requires her to be extremely careful. Diligent hand washing, personal hygiene, avoiding close contact with other people are necessary. Passive immunoprophylaxis comprising the administration of immunoglobulins is used in organ transplant recipients (in order to reduce the severity of symptoms, not to prevent the infection). An active prophylactic measures i.e. vaccination against HCMV is not as yet available (Ho, 2008).

\section{Conclusion}

The presented characteristics of HCMV infection indicates that it may occur at all ages, from intrauterinal development to the elderlies. The consequences of infection are clinically visible either directly or years after, and the clinical course of disease is very diverse. The diagnostic and therapeutic methods that are currently used are not satisfactory. Therefore, an effective vaccine seems to be the only measure in order to prevent the effects of HCMV infection.

\section{Acknowledgements}

This study was supported by the Polish Government through a grant No N N407 059737 from the Ministry of Science and Higher Education (to Magdalena Figlerowicz).

\section{References}

Adler S.P., Nigro G., Pereira L. (2007) Recent advances in the prevention and treatment of congenital cytomegalovirus infections. Semin. Perinatol. 31: 10-18.

Alford C.A., Stagno S., Pass R.F., Britt W.J. (1990) Congenital and perinatal cytomegalovirus infections. Rev. Infect. Dis. 12: 745-753.

Al-Ghamdi A., Jiman-Fatani A.A., El-Banna H. (2011) Role of Chlamydia pneumoniae, helicobacter pylori and cytomegalovirus in coronary artery disease. Pak. J. Pharm. Sci. 24: 95-101.

Cheng J., Ke Q., Jin Z., Wang H., Kocher O., Morgan J.P., Zhang J., Crumpacker C.S. (2009) Cytomegalovirus infection causes an increase of arterial blood pressure. Plos. Pathog. 5: e1000427.

Campbell A.E., Cavanaugh V.J., Slater J.S. (2008) The salivary glands as a privileged site of cytomegalovirus immune evasion and persistence. Med. Microbiol. Immunol. 197: 205-213.
Cannon M.J., Davis K.F. (2005) Washing our hands of congenital cytomegalovirus diseases epidemic. BMC Public Health. 5: 70.

Daley E., Emson C., Guignabert C., de Waal Malefyt R., Louten J., Kurup V.P., Hogaboam C., Taraseviciene-Stewart L., Voelkel N.F., Rabinivitch M. et al. (2008) Pulmonary arterial remodeling induced by a Th2 immune response. J. Exp. Med. 205: 361-372.

Malarowska M., Mazur-Melewska K., Mania A., Kemnitz P., Cudnoch K., Kowala-Piaskowska A., Służewski W., MozerLisewska I., Figlerowicz M. (2009) Charakterystyka kliniczna cytomegalii wrodzonej i nabytej u dzieci na podstawie własnych obserwacji. Przegl. Pediatr. 39: 178-182.

Figlerowicz M., Mania A., Mazur-Melewska K., Kemnitz P., Malarowska M., Cudnoch K., Służewski W. (2011) Replikacja HCMV w surowicy krwi i moczu dzieci z cytomegalią wrodzona. Pediatr. Pol. 1: 15-21.

Gerhz R.C. (1991) Human Cytomegalovirus: Biology and Clinical Perspectives. Adv. Pediatr. 38: 203-231.

Gerna G., Percivalle E., Baldanti F., Sozzani S., Lanzarini P., Genini E., Lilleri D., Revello M.G. (2000) Human cytomegalovirus replicates abortively in polymorphonuclear leucocytes after transfer from infected endothelial cells via transient microfusion events. J. Virol. 74: 5629-5638.

Grefte A., van der Giessen M., von Son W., The TH. (1993) Circulating cytomegalovirus (CMV)-infected endothelial cells in patients with an active CMV infection. J. Infect. Dis. 167: 270-277.

Grefte A., Harmsen M.C., van der Giessen M., Knollema S., van Son W.J., The T.H. (1994) Presence of human cytomegalovirus (HCMV) immediate early mRNA but not ppUL83 (lower matrix protein pp65) $m R N A$ in polymorphonuclear and mononuclear leucocytes during active HCMV infection. J. Gen. Virol. 75: 1989-1998.

Grundy J.E., Lawson K.M., MacCormac L.P., Fletcher J.M., Yong K.L. (1998) Cytomegalovirus-infected endothelial cells recruit neutrophils by the secretion of $C-X$-C chemokines and transmit virus by direct neutrophil-endothelial cell contact and during neutrophil transendothelial migration. J. Infect. Dis. 177: 1465-1474.

Hamprecht K., Maschmann J., Jahn G., Poets C.F., Goelz R. (2008) Cytomegalovirus transmission to preterm infants during lactation. J. Clin. Virol. 41: 198-205.

Ho M. (1990) Epidemiology of cytomegalovirus infections. Rev. Infect. Dis. 12: 701.

Ho M. (2008) The history of cytomegalovirus and its diseases. Med. Microbiol. Immunol. 197: 65-73.

Ismail A., Khosravi H., Olson H. (1999) The role of infection in atherosclerosis and coronary artery disease: a new therapeutic target. Heart Dis. 1: 233-240.

Malm G., Engman M.L. (2007) Congenital cytomegalovirus infections. Semin. Fetal Neonatol. Med. 12: 154-159.

Michaels M.G. (2007) Treatment of congenital cytomegalovirus: where are we now? Expert Rev. Anti Infect. Ther. 5: 441-448.

Milewska-Bobula B., Rowecka-Trzebicka K., Lipka B., Maciejewski Z., Dobrzańska A., Kassur-Siemieńska B. (1992) 
Charakterystyka kliniczna zakażeń wirusem cytomegalii $u$ niemowląt na podstawie własnych obserwacji. Pol. Tyg. Lek. 37: 781-783.

Murhy F.A., Fauquet C.M., Bishop D.H.L. (1995) Herpesviridae family. In: Virus taxonomy. Classification and nomenclature of viruses. Sixth Report of the International Committee on Taxonomy of Viruses, Springer-Verlag, Wien, New York, p. 114.

Pass R.F. (2001) Cytomegalovirus. In: Fields Virology, ed. Knipe D.M., Howley P.M., Lippincott, Williams \&Wilkins New York, p. 2675-2730.

Percivalle E., Revello M.G., Vago L., Morini F., Gerna G. (1993) Circulating endothelial giant cells permissive for human cytomegalovirus (HCMV) are detected in disseminated HCMV infections with organ involvement. J. Clin. Invest. 92: 663-670.

Peterslund N.A. (1991) Herpesvirus infection: an overview of clinical manifestation. Scand. J. Infect. Dis. 80: 15-20.

Saetta A., Fanourakis G., Agapitos E., Davaris P.S. (2000) Atherosclerosis of the carotid artery: absence of evidence for CMV involvement in atheroma formation. Cardiovasc. Pathol. 9: 181-183.

Sinclair J. (2008) Human cytomegalovirus: Latency and reactivation in the myeloid lineage. J. Clin. Virol. 41: 180-185.
Sinzger C., Plachter B., Grefte A., The T.H., Jahn G. (1996) Tissue macrophages are infected by human cytomegalovirus in vitro. J. Infect. Dis. 173: 240-245.

Sinzger C. (2008) Entry route of HCMV into endothelial cells. J. Clin. Virol. 41: 174-179.

Soderberg-Naucler C. (2006) Does cytomegalovirus play a causative role in the development of various inflammatory diseases and cancer? J. Intern. Med. 259: 219-246.

van de Berg P.J., van Stijn A., ten Berge I.J.M., van Lier R.A.W. (2008) A fingerprint left by cytomegalovirus infection in the human T cell compartment. J. Clin. Virol. 41: 213-317.

van de Berg P.J., Griffiths S.J., Yong S.L., Macaulay R., Bemelman F.I., Jackson S., Henson S.M., ten Berge I.J., Akbar A.N., van Lier R.A. (2010) Cytomegalovirus infection reduces telomere length of the circulating $T$ cell pool. J. Immunol. 184: 3417-3423.

Waller E.C.P., Day E., Sissons J.G.P., Wills M.R. (2008) Dynamics of $T$ cell memory in human cytomegalovirus infection. Med. Microbiol. Immunol. 197: 83-96.

Zhang X.W., Li F., Yu X.W., Shi X.W., Shi J., Zhang J.P. (2007) Physical and intellectual development in children with asymptomatic congenital cytomegalovirus infection: a longitudinal cohort study in Qinba mountain area, China. J. Clin. Virol. 40: 180-185. 